\title{
Dissection of the cervical internal carotid artery. The role of Doppler/Duplex studies and conservative management
}

\author{
M S M Eljamel, P R D Humphrey, M D M Shaw
}

\begin{abstract}
Cervical internal carotid dissection is not rare. Doppler ultrasound screening of young patients presenting with stroke, identified 10 patients with reduced common and internal carotid blood flow without any evidence of atheroma. Eight, on angiography proved to have a dissection of the cervical internal carotid artery. All were managed conservatively. Seven received anticoagulant therapy, stopping any further neurological symptoms.
\end{abstract}

Since Jentzer ${ }^{1}$ reported a case of a spontaneously dissecting aneurysm of the internal carotid artery in 1954, an increasingly large number of reports have found a higher incidence than had initially been thought. ${ }^{2-5}$ Spontaneous resolution, with a good recovery, has been documented. ${ }^{3-8}$ This report examines the screening of young patients, with stroke or transient ischaemic attacks (TIAs), using Doppler ultrasonography to decide which patients should undergo angiography to detect internal carotid artery dissection; the results of non surgical management of this condition are also given.

\section{Patients}

Eight patients, in whom dissection of the cervical internal carotid artery was diagnosed on angiography, were admitted to the regional unit from a population of approximately three million, during the period September 1986 to May 1988. During this time 700 Doppler/

Table 1 Clinical details

\begin{tabular}{|c|c|c|c|c|}
\hline Case no & Patient & Clinical features & Event & Factors \\
\hline 1 & $14 \mathrm{M}$ & headache & stuttering & \\
\hline 2 & $17 \mathrm{M}$ & $\begin{array}{l}\text { Lumn paresis } \\
\text { headache } \\
\mathrm{R} \text { umn paresis } \\
\text { dysphasia }\end{array}$ & $\begin{array}{l}\text { stroke } 10 \text { days } \\
\text { stuttering } \\
\text { stroke } 10 \text { days }\end{array}$ & $\begin{array}{l}\text { smoker } \\
\text { neck trauma }\end{array}$ \\
\hline 3 & $37 \mathrm{~F}$ & $\begin{array}{l}\mathrm{R} \text { umn paresis } \\
\text { dysphasia }\end{array}$ & $\begin{array}{l}\text { stuttering } \\
\text { stroke } 14 \text { days }\end{array}$ & $\begin{array}{l}\text { BP } 170 / 90 \\
\text { oral } \\
\text { contraceptive }\end{array}$ \\
\hline 4 & $37 \mathrm{~F}$ & $\begin{array}{l}\text { headache } \\
R \text { umn paresis } \\
\text { paraesthesia } R \text { arm } \\
\text { dysphasia }\end{array}$ & $\begin{array}{l}5 \text { TIAs } \\
\text { (45 min each) } \\
7 \text { days }\end{array}$ & $\begin{array}{l}\text { BP } 160 / 90 \\
\text { smoker } \\
\text { nasal trauma }\end{array}$ \\
\hline 5 & $38 \mathrm{M}$ & $\begin{array}{l}\text { paraesthesia } R \text { face } \\
\text { amaurosis fugax } \\
\text { carotid bruit }\end{array}$ & $\begin{array}{l}2 \text { TIAs } \\
2 \text { weeks }\end{array}$ & smoker \\
\hline 6 & $40 \mathrm{M}$ & $\begin{array}{l}\mathbf{R} \text { hemiparesis } \\
\text { dysphasia }\end{array}$ & $\begin{array}{l}2 \text { strokes } \\
4 \text { yrs \& now }\end{array}$ & smoker \\
\hline 7 & $47 \mathrm{~F}$ & $\begin{array}{l}\text { slow visual loss } \\
\text { paraesthesia } L \text { arm } \\
\text { dysphasia }\end{array}$ & $\begin{array}{l}\text { strokes }+++ \\
\text { over } 3 \text { yrs }\end{array}$ & BP $180 / 120$ \\
\hline 8 & $55 \mathrm{M}$ & $\begin{array}{l}R \text { umn paresis } \\
\text { paraesthesia } R \text { arm }\end{array}$ & $\begin{array}{l}\text { TIAs } 18 \text { mths } \\
\text { then progressive } \\
\text { stroke } 3 \text { mths }\end{array}$ & $\begin{array}{l}\text { BP } 150 / 90 \\
\text { ex-smoker }\end{array}$ \\
\hline
\end{tabular}

Duplex examinations were carried out for vascular disease.

The details of the clinical presentations are summarised in table 1 . The male:female ratio was $5: 3$ and the age range 14 to 55 years. Cerebral hemisphere signs were present in all cases. Transient ischaemic attacks occurred in three cases, stuttering stroke (that is, a stroke evolving in a stepwise fashion) in a further three cases, and multiple strokes in the other two patients. One patient began with transient ischaemic attacks and subsequently developed a stuttering stroke (case 8 ). Of the multiple strokes, one (case 6) had a left hemisphere stroke four years earlier and had undergone an extracranial-intracranial bypass procedure, elsewhere, on the right side in addition to being given antiplatelet agents, and the second case (case 7) experienced progressive visual failure over three years from multiple cerebral infarcts. In only one case was a carotid bruit found on examination.

More than half the patients were or had been smokers. Using the definitions accepted in the Framingham Study, ${ }^{9}$ four patients were hypertensive, three falling into the definite and one into the borderline categories. Two patients (cases 1 and 7) had family histories of vascular disease. Two had experienced recent minor trauma to the neck: case 2 as the result of a kick to the opposite side of the neck during martial arts training and case 4 rotational effects after being struck on the nose by a falling object. Case 8 had sustained a moderately severe head injury 20 years earlier.

\section{Investigations}

Computerised tomography (CT) scans confirmed the presence of infarcts in $75 \%$ of cases. The majority were in the cortex and the subcortical white matter but in case 1 were restricted to the capsule and the caudate nucleus (fig 1).

Duplex ultrasonic and CW Doppler examinations (using a Diasonics Duplex CV 400 scanner and a Kranzbuhler $761 \mathrm{CW}$ flowmeter) were used as screening tests in all cases. Reduced flow in both the common and internal carotid arteries, upon the side appropriate to the clinical features was found in all cases (fig 2). Atheroma was detected in 3 cases, 2 of whom had bilateral disease. However in none of these three was the atheroma severe enough to account for the reduced flows in the common and internal carotid arteries. Reversal of flow through the supraorbital vessels occurred in 
Figure 1 Caudate nucleus infarct on $C T$ (arrow indicates).

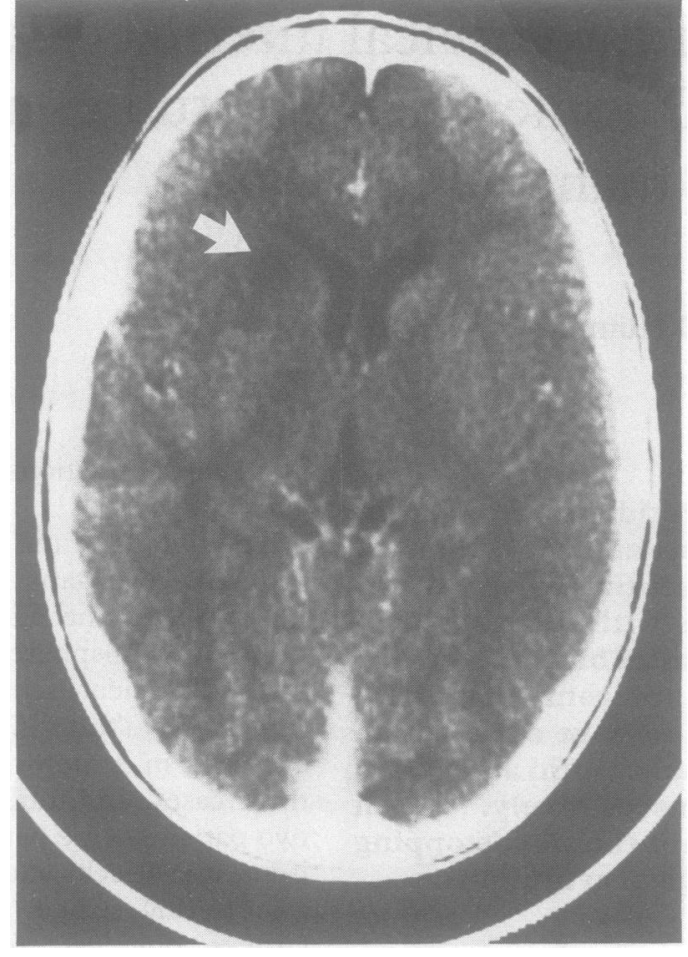

only one case. The dissection itself was seen on Duplex scanning (fig 3) in two cases. Five patients had Duplex Scanning within two weeks of onset of symptoms; two within three months of the last symptom and one at a year.

Cerebral digital subtraction angiography was carried out by intra-arterial injection in all cases (table 2). Each case showed the "string sign", (fig 4a) which is considered to be diagnostic for the condition, in the cervical internal carotid artery. The lesion was left sided in five, right sided in two and bilateral in one.

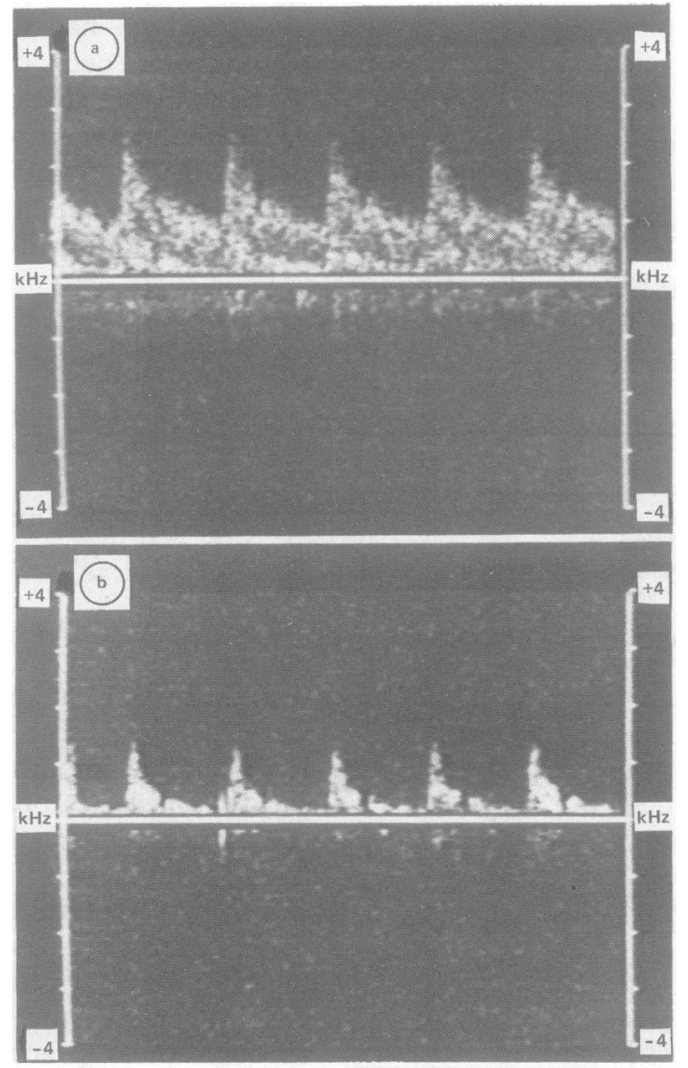

The other angiographic findings were:

1) Embolic occlusion of one or more of the distal intracranial arteries in four patients; 2) "beading" of the contralateral internal carotid artery compatible with fibromuscular dysplasia was present in two patients; 3) an aneurysm arising from the cervical portion of the internal carotid artery, adjacent to the skull base in one patient (fig $4 a$ and b) mild atheroma was demonstrated in only two patients, both of whom had bilateral disease demonstrated on ultrasonic examination.

Two additional young patients, aged nine and 22 , who had reduced internal carotid flow on Doppler studies, and no other abnormality in the cervical carotid arteries even on angiography, had multiple intracranial vascular occlusions of the distal branches of the middle and anterior cerebral arteries. These, therefore represent false positives.

One patient, aged 43 , had a left hemiplegia and right Horner's sign with reduced right internal carotid artery flow. Angiography was not thought justifiable as his deficit was complete.

\section{Management}

Anticoagulation, using heparin initially and warfarin for twelve months, was started within three weeks of the ictus in four patients, three of whom presented with stuttering strokes. The outcome in each was good (table 3), even though two had further minor attacks before full anticoagulation was achieved. Three of the four patients who were initially treated with antiplatelet agents (aspirin in all cases plus persantin in cases 5 and 6) continued to have attacks and were therefore switched to anticoagulants, with symptomatic control. Case 6 had had a right sided extra/intracranial bypass operation carried out following the first stroke (which affected the left cerebral hemisphere) suffered four years before presentation to this unit.

Repeat Doppler studies after anticoagulant treatment was instituted showed an improved flow in four cases, three of whom had been anticoagulated within three weeks of the ictus.

\section{Discussion}

Cervical internal carotid dissection is a more

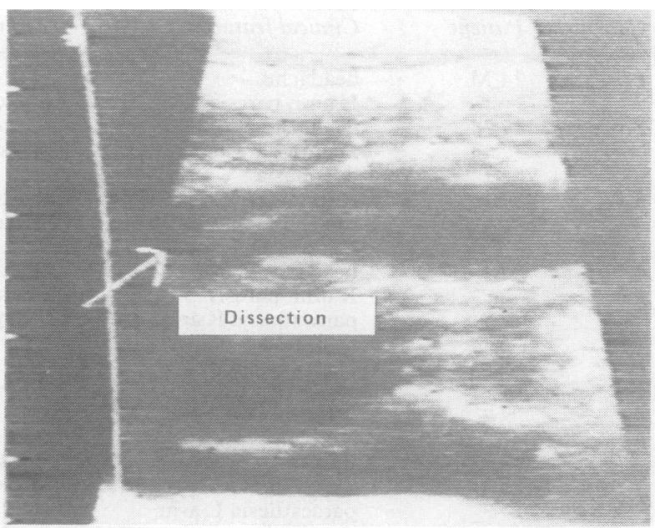

Figure 3 Fixed linear shape (arrow indicates) in lumen of internal carotid artery above bifurcation thought to be secondary to dissection. 
Table 2 Investigations

\begin{tabular}{|c|c|c|c|c|}
\hline Case no & Side & $C T$ infarct & Doppler ${ }^{\star}$ & Angio (int carotid) \\
\hline 1 & $\mathbf{R}$ & capsule/caudate & flow reduced & $\begin{array}{l}\text { “string" sign } \\
\text { dysplasia }{ }^{\star \star} \\
\text { distal occl" }\end{array}$ \\
\hline 2 & L & $\begin{array}{l}\text { cortex } \\
\text { white matter }\end{array}$ & flow reduced & $\begin{array}{l}\text { "string" sign } \\
\text { distal occl" }\end{array}$ \\
\hline $\begin{array}{l}3 \\
4\end{array}$ & $\mathbf{L}$ & cortex & $\begin{array}{l}\text { flow reduced } \\
\text { atheroma/flow } \\
\text { reduced }\end{array}$ & $\begin{array}{l}\text { "string" sign } \\
\text { "string" sign }\end{array}$ \\
\hline 5 & $\mathbf{R}$ & - & $\begin{array}{l}\text { flow reduced/ } \\
\text { reversed supra-orbital flow }\end{array}$ & $\begin{array}{l}\text { "string" sign } \\
\text { distal occl" } \\
\text { ec aneurysm }\end{array}$ \\
\hline 6 & $R$ and $L$ & $\begin{array}{l}\text { old cortex/ } \\
\text { white matter }\end{array}$ & L flow reduced & $\begin{array}{l}\text { "string" sign } \\
\text { mild stenosis }\end{array}$ \\
\hline 7 & $\mathbf{L}$ & $\begin{array}{l}\text { multiple cortex/ } \\
\text { white matter }\end{array}$ & $\begin{array}{l}\text { flow reduced } \\
\text { bilat atheroma }\end{array}$ & $\begin{array}{l}\text { "string" sign } \\
\text { dysplasia } \star \star \\
\text { distal occl" } \\
\text { bilat atheroma }\end{array}$ \\
\hline 8 & $\mathbf{L}$ & $\begin{array}{l}\text { multiple cortex/ } \\
\text { white matter }\end{array}$ & $\begin{array}{l}\text { flow reduced } \\
\text { bilat atheroma }\end{array}$ & $\begin{array}{l}\text { "string" sign } \\
\text { bilat atheroma }\end{array}$ \\
\hline
\end{tabular}

* Reduced flow was found in the appropriate internal and common carotid arteries. $\star \star$ Fibromuscular dysplasia ec-extracrania

common cause of cerebral ischaemia than has been previously recognised. ${ }^{2-5}$ Its pathogenesis is not fully understood, but some conditions, which are associated, may be causal agents; these include fibromuscular dysplasia of the internal carotid and the renal arteries which has been reported in $10-20 \%$ of cases, ${ }^{2310-14}$ cystic medial necrosis, ${ }^{14}{ }^{15}$ hypertension, atheroma, a family history of arteriosclerosis, and phaeochromocytoma. ${ }^{16}$ Two of this current series showed angiographic appearances compatible with the diagnosis of fibromuscular dysplasia, four were hypertensive (including one patient who was borderline as judged by the Framingham criteria), ${ }^{9}$ two had atheromatous disease seen on angiography and two a family history of arterial disease. Spontaneous internal carotid artery dissection is well recognised. The significance of the patients with minor trauma remains uncertain as there has been no case control study to our knowledge. Most centres in the United Kingdom do not perform angiograms on all young patients with TIAs or stroke; however a history of recent trauma may influence this decision creating a biased impression that dissection usually follows trauma. This study used Doppler/Duplex scanning as the discriminator and a history of minor trauma was elicited in two of the eight patients. Minor trauma in the form of either, a minor direct blunt injury to the neck, or rotation (particularly if combined with an element of flexion/extension) of the neck, cannot be excluded as an initiating factor. ${ }^{17-19}$ In centres where all young stroke patients have had angiograms, cervical carotid dissection is the dominant cause. ${ }^{20}$

Three patients had ipsilateral headache at presentation as described previously. ${ }^{21}$ The literature suggests that carotid bruits are found at the time of presentation in $10-50 \%$ of cases whilst occulosympathetic paresis (Horner's
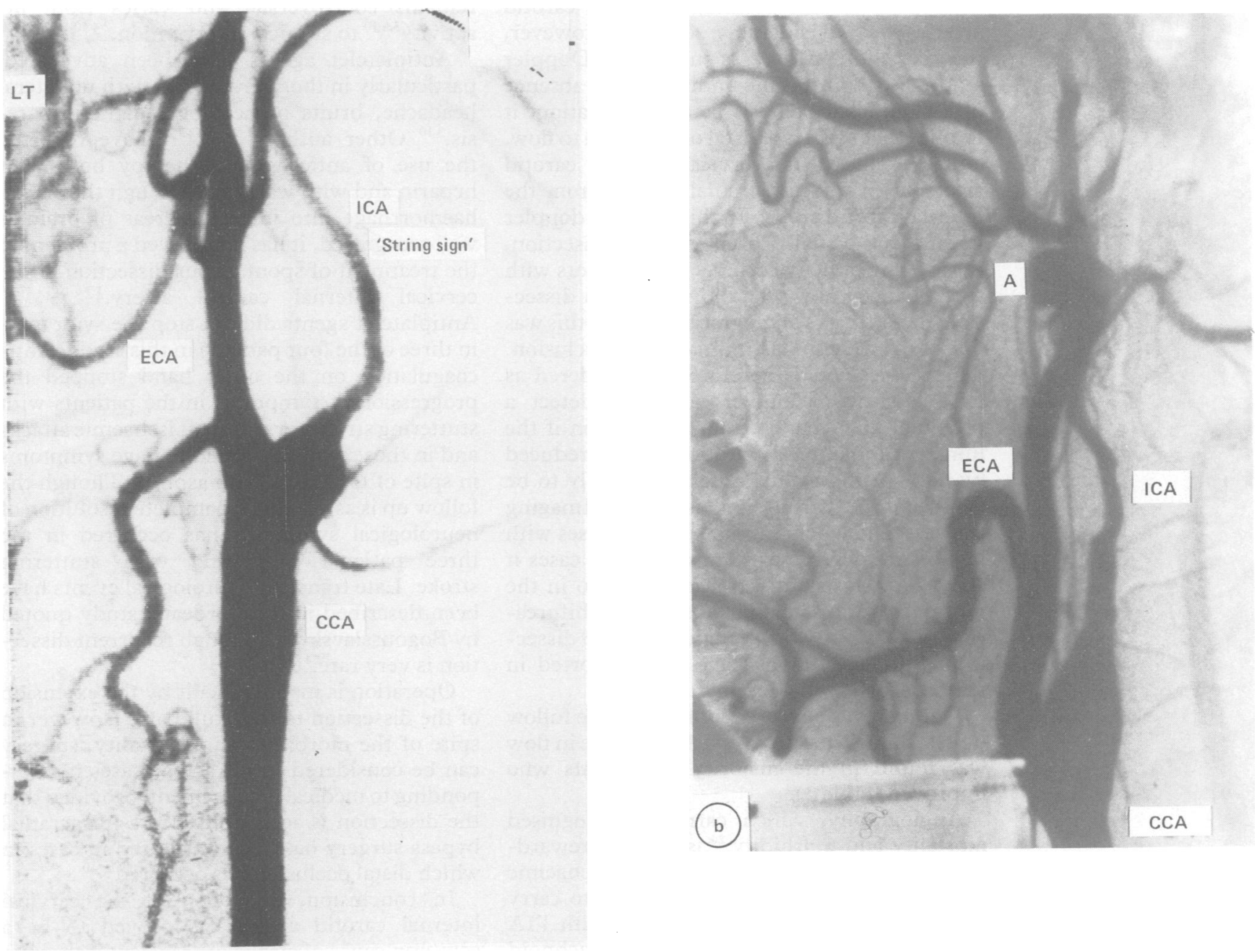

Figure 4 Angiogram a: string sign, b) aneurysm (A). CCA-common carotid artery, ICA-internal carotid artery, ECA-external carotid artery. 
Table 3 Treatment and follow up

\begin{tabular}{|c|c|c|c|c|c|c|}
\hline $\begin{array}{l}\text { Case } \\
\text { No } \\
1 \\
2 \\
3\end{array}$ & \multicolumn{2}{|c|}{$\begin{array}{l}\text { Therapy } \\
\text { Anti-Coag/Platelet }\end{array}$} & $\begin{array}{l}\text { Time Ictus/ } \\
\text { Therapy }\end{array}$ & $\begin{array}{l}\text { Doppler Flow } \\
\text { Change }\end{array}$ & $\begin{array}{l}\text { Outcome } \\
\text { good }\end{array}$ & $\begin{array}{l}\text { Follow up after } \\
\text { this therapy }\end{array}$ \\
\hline $\begin{array}{l}1 \\
2 \\
3 \\
4 \\
5 \\
6 \\
7 \\
8\end{array}$ & $\begin{array}{l}+ \\
+ \\
+ \\
+ \\
+ \\
+ \\
+ \\
+\end{array}$ & $\begin{array}{l}- \\
- \\
- \\
\overline{+} \\
+ \\
+ \\
+\end{array}$ & $\begin{array}{l}13 \text { days } \\
10 \text { days } \\
20 \text { days } \\
1 \text { day } \\
0 \text { days } \\
4 \text { mths } \\
24 \text { mths } \\
2 \text { mths }\end{array}$ & $\begin{array}{l}\text { improved } \\
\text { improved } \\
\text { none } \\
\text { improved } \\
\text { improved } \\
\text { none } \\
\text { none } \\
\text { improved }\end{array}$ & $\begin{array}{l}\text { good } \\
\text { good } \\
\text { good } \\
\text { good } \\
\text { good } \\
\text { old R hemiparesis } \\
\text { poor vision } \\
\text { good }\end{array}$ & $\begin{array}{l}14 \text { mths } \\
31 \text { mths } \\
16 \text { mths } \\
15 \text { mths } \\
22 \text { mths } \\
12 \text { mths } \\
14 \text { mths } \\
14 \text { mths }\end{array}$ \\
\hline
\end{tabular}

Cases 6,7 , and 8 all had further ischaemic events on aspirin and were therefore anticoagulated.

Good outcome = full functional recovery and no further ischaemic events following establishment of therapy.

Cases 6 and 7 continued with their pre-anticoagulation deficit.

syndrome) which is thought to be one of the cardinal signs, is present in $21-58 \%$. Both may spontaneously resolve in the first week. ${ }^{3101314}$ Carotid bruits were heard in one case but no angiographically proven case demonstrateci an occulosympathetic paresis.

The Doppler/Duplex examination is a simple non invasive test, carrying little risk and in experienced hands is a reliable method of screening patients presenting with carotid disease. $^{22}$ Eight cases of angiographically proven dissection of the cervical internal carotid artery have been discovered in young patients having strokes.

Doppler/Duplex examinations were carried out in all eight cases on presentation before angiography, and showed that the blood flow in the common and proximal internal carotid arteries was considerably reduced. However, the reduction in flow as judged on Doppler studies is a non specific finding. In the absence of a significant stenosis at the bifurcation, it implies that there is a distal obstruction to flow, either in the distal cervical internal carotid artery or in the intracranial run off from the internal carotid artery. In this unit this doppler finding has usually been due to dissection, there being only two other young patients with such reduced flow who did not have a dissection; in both cases angiography showed this was due to intracranial multi-vessel occlusion. These cases could therefore be considered as false positives. Doppler will only detect a proximal flow change from a dissection if the lumen of the internal carotid artery is reduced by $60 \%$ or more; this criterion is likely to be fulfilled if the "string sign" is present. Imaging the vessel may help in some of these cases with less severe degrees of stenosis; in two cases it showed a consistent intravascular echo in the internal carotid artery just distal to the bifurcation (fig 3). This was thought to be the dissection. Similar findings have been reported in vertebral artery dissection. ${ }^{23}$

Doppler was also used as an objective follow up test to monitor progress. An increase in flow was found in the majority of patients who improved (table 3).

Angiography, which carries a recognised mortality and morbidity, ${ }^{24}$ is often unrewarding in the young when investigating ischaemic disease. We believe it is not justified to carry out angiography in all young patients with TIA or stroke not attributable to subarachnoid haemorrhage. Nor do we usually angiogram patients with a dense stroke; there was one other young patient with a left hemiplegia and right Horner's syndrome with reduced flow in the right carotid artery in whom angiography was not performed, because his deficit was complete. It is therefore not possible to determine a false negative rate for Doppler/ Duplex scanning in carotid dissection. All the cases reported here had TIAs or a partial deficit; angiography was performed on the basis of the Doppler/duplex findings before a decision about anticoagulation. Each showed the "string sign" and half, distal occlusion. The frequency of the "string sign" was similar to previously reported series but distal occlusion seems to be two and five times more common in this group..$^{2-410111314}$

Management of internal carotid dissection remains controversial and varies from inactivity $^{3410}$ to surgical intervention..$^{241011142526}$

Antiplatelet agents have been advocated, particularly in those presenting with unilateral headache, bruits or occulosympathetic paresis. $^{310}$ Other authors ${ }^{5101327-29}$ have reported the use of anticoagulant therapy both with heparin and with warfarin. Though the risk of haemorrhage into infarcted areas of brain is well recognised, it has not proved a problem in the treatment of spontaneous dissection of the cervical internal carotid artery. $356101327-29$ Antiplatelet agents did not stop the symptoms in three of the four patients in this study. Anticoagulation on the other hand stopped the progression of symptoms in the patients with stuttering strokes or transient ischaemic attacks and in those who continued to have symptoms in spite of treatment with aspirin. Though the follow up is as yet short, complete resolution of neurological symptoms has occurred in the three patients presenting with stuttering stroke. Late transient neurological events have been described in the Bordeaux study quoted by Bogousslavsky, ${ }^{30}$ although recurrent dissection is very rare. ${ }^{13} 19$

Operation is made difficult by the extension of the dissection to the skull base. However in spite of the morbidity and mortality, surgery can be considered in refractory cases not responding to medical management, provided that the dissection is accessible. Extra-intracranial bypass surgery has been advocated in cases in which distal occlusion has occurred. ${ }^{310}$

In conclusion, dissection of the cervical internal carotid artery has proved to be a common cause of stroke or transient ischaemic attack in the young patient presenting to this unit. More minor cases may well go undetec- 
ted. Doppler/Duplex ultrasonography would seem to be a useful screening test and helps make the decision as to whether one should proceed to angiography in this young age group. Anticoagulation would seem to be the treatment of choice in those with recurrent or progressive hemisphere neurological symptoms and signs whose deficit is not complete.

We are grateful to the Medical Research Council, The Chest, Heart and Stroke Association, and the Merseyside Research Association for financial help.

1 Jentzer A. Dissecting aneurysm of the left internal carotid artery. Angiology 1954;5:232-4.

2 Ehrenfeld WK, Wylie EJ. Spontaneous dissection of internal carotid artery. Arch Surg 1976;111:1294-301.

3 Mokri B, Sundt TM, Houser OW, Piepgras DG Spontaneous dissection of the cervical internal carotid artery. Ann Neurol 1986;19:126-38.

4 Bradac GB, Kaernbach A, Bolk-Weischedel D, Finck GA. Spontaneous dissecting aneurysm of cervical cerebral arteries; report of six cases and review of the literature. Neuroradiology 1981;21:149-54.

5 Fisher CM, Ojemann RG, Roberson GH. Spontaneous dissection of cervico-cerebral arteries. Can J Neurol Sci dissection of

6 Gee W, Kaupp HA, McDonald KM, Lin FZ, Curry JL. Spontaneous dissection of internal carotid arteries. Arch Surg 1980;115:944-9.

7 Friedman WA, Day AL, Quisling RG. Cervical dissecting aneurysm. Neurology 1980;7:207-13.

8 Deramond H, Remond A, Rosat P, Froissart M, Dobbelaere $P$, Trinez G. Spontaneous evolution of non traumatic dissecting aneurysms of the cervical portion of the interna carotid artery. $J$ Neuroradiology 1980;7:167-82.

9 Sacco RL, Wolfe PA, Bharoumi BE, et al. Subarachnoid haemorrhage: natural history, prognosis and precursive factors in the Framingham study. Neurology (Cleveland) 1984;34:847-54.

10 Sellier N, Chiras J, Benhamou M, Bories J. Spontaneous dissection of the internal carotid artery; clinical radiological and evolutive features. J Neuroradiology 1983 10:243-59.

11 O'Dwyer JA, Moscow N, Trevor R, Ehrenfeld WK, Newton TH. Spontaneous dissection of the carotid artery Neuroradiology 1980;137:379-85.
12 Houser OW, Mokki B, Sundt TM, Baker HL, Reese DF Spontaneous cervical cephalic arterial dissection and its residuum: angiographic spectrum. $A J N R$ 1984;5:27-34.

13 Bogousslavsky J, Despland PA, Regli F. Spontaneous carotid dissection with acute stroke. Arch Neurol 1987;44:137-40.

14 Luken MG, Ascherl GF, Correll JW, Hilal SK Spontaneous dissecting aneurysm of the extracranial internal carotid artery. Clin Neurosurg 1979;26:353-75.

15 Bostrom K, Liliequist B. Primary dissecting aneurysm of the extracranial part of the internal carotid and vertebral arteries. Neurology (Minneapolis) 1967;17:179-86.

16 Gulliford MC, Hawkins CP, Murphy RP. Spontaneous dissection of the carotid artery and phaeochromocytoma Brit J Hosp Med 1986;35:416.

17 Momose KJ, New PFJ. Non-atheromatous stenosis and occlusion of the internal carotid artery and its main branches. AJR 1973;118:550-66.

18 Stringer WL, Kelly DL. Traumatic dissection of the extracranial internal carotid artery. Neurosurgery 1980; 6:123-30.

19 Rohr J, Gauthier S. Hematomes dissequants spontanes successifs a 3 ans et demi d'intervalle des deux arteres successifs a 3 ans et demi d'intervalle des deux arteres

20 Bogousslavsky J. Ichaemic strokes in adults younger than 30 years of age. Arch Neurol 1987;44:479-82.

21 Fischer CM. The headaches and pain of spontaneous carotid dissection. Headache 1982;22:60-5.

22 Humphrey P, Sandercock P, Slattery J. Carotid ultrasound investigation methods to improve avoidance of stroke due to angiography. J Neurol Neurosurg Psychiatry. (In press).

23 Touboul PJ, Mas JL, Bousser MG, Laplane D. Duplex scanning in extracranial vertebral artery dissection. Stroke 1988;19:116-21.

24 Loew K, Murie JA. Cerebral angiography for cerebrovascular disease: the risks. Brit $J$ Surg 1988;75:428-30.

25 Brown OL, Armitage JL. Spontaneous dissecting aneurysm of the cervical internal carotid artery. $A J R$ 1973;118: 648-53.

26 Hodge CJ, Lee SH. Spontaneous dissecting cervical carotid artery aneurysm. Neurosurgery 1982;10:93-5.

27 Benoit BG, Nabavi NL, Pryse-Phillips WE, Russell WA Clinical features of spontaneous carotid artery dissection (abstract). Stroke 1980;11:132.

28 Chapleau CE, Robertson JT. Spontaneous cervical carotid dissection; outpatient treatment with continuous heparin infusion using a totally implantable infusion device. Neurosurgery 1981;8:83-7.

29 McNeill DH, Dreisbach J, Marsden RJ. Spontaneous dissection of the internal carotid artery; its conservative management with heparin sodium. Arch Neurol 1980; 37:54-5.

30 Bogousslavsky J. Dissections of the cerebral arteries: clinical effects. Current Opinion in Neurology and Neurosurgery 1988;1:63-8. 